\title{
Passeio na biblioteca de Murilo Mendes
}

Maria Betânia Amoroso (UNICAMP)

No Centro de Estudos Murilo Mendes, o visitante é surpreendido, em primeiro lugar, pela recepção amiga e atenciosa concedida ao pesquisador e depois pelo material ali preservado: coleção de arte vistosa, biblioteca bem organizada, fotos e documentos ${ }^{1}$. Surpreendente também a vitalidade exibida durante as comemorações do centenário do nascimento de Murilo Mendes, no ano passado. $^{2}$

As vantagens desse centro ativo e da data comemorativa estão justamente em propiciar a oportunidade para um balanço geral, no caso, uma chance para se avaliar como vem sendo estudado Murilo Mendes.

Sua coleção de arte, que recebeu o devido destaque na exposição, sem dúvida mereceria maior atenção dos estudiosos ${ }^{1}$. Entre os documentos, as cartas enviadas por Murilo Mendes para Alceu Amoroso Lima merecem também atenção especial. Foram 42 anos de correspondência constante: carta após carta, o poeta mineiro reconhece a autoridade do crítico literário e, ao mesmo tempo, reforça seu vínculo de "discípulo" com o grande "mestre" católico. Iniciada com o poeta ainda em Minas, sofre alterações no itinerário com a transferência de Murilo Mendes para Roma, em 1957. Da capital oficial do catolicismo, ele continuará a acompanhar as atividades intelectuais e de militante de Tristão de Athayde, no Centro D. Vital, na universidade e enviará relatos ao amigo sobre seu projeto poético, sua vida romana e sobre sua própria fé. 
Como decorrência, sem dúvida, das visitas ao CEMM, mas também como conseqüência do interesse que a obra de Murilo Mendes vem despertando entre jovens pesquisadores, nasce este artigo. A intenção não é, contudo, analisar literariamente a produção menos estudada do poeta e tampouco desenhar um quadro das relações de Murilo Mendes com Alceu Amoroso Lima no horizonte do catolicismo brasileiro. A partir das cartas, dos livros lidos e anotados pelo poeta, depositados na biblioteca, da leitura da obra de Murilo Mendes e das obras já escritas sobre ele, foi possível sublinhar alguns elementos. Entre eles, a persistente relação do poeta, mesmo durante os anos italianos, com o ambiente católico do Brasil; a ausência de indícios de um envolvimento maior de Murilo Mendes com questões culturais italianas marcantes, nas décadas que seguiram a Segunda Guerra, em particular, o papel do intelectual na construção de uma nova sociedade e a relação entre catolicismo e comunismo, nesse projeto de reconstrução; a descrição ou a freqüente citação, da cena da conversão de Murilo Mendes ao catolicismo, no velório do amigo Ismael Nery, que pode assumir outros contornos, se vista sob outra luz; o doloroso deslocamento do poeta "poliédrico" no mundo europeu, apesar dos sinais que confirmam sua inserção entre artistas e intelectuais, espanhóis, franceses, italianos.

Desde já, duas ressalvas: a primeira, as observações feitas e os elementos apontados neste artigo são regidos, sobretudo, por interesse pela biografia intelectual de Murilo Mendes; a segunda, essas observações e elementos, ao entrarem como partes do jogo alquímico da poesia, sofrem transformações. Disso resulta algo eminentemente literário e só enquanto tal pode ser tratado. A aproximação ao particularíssimo universo poético é aqui apenas indicada, ao se afirmar a importância do Mistério na vida e na obra de Murilo Mendes. 
II.

O diálogo entre Murilo Mendes e Amoroso Lima (passível de ser reconstruído, levando-se em conta a correspondência preservada no CEMM) pode ter como primeiro elemento, na ordem do tempo, a carta escrita pelo poeta para o crítico católico em 23 de fevereiro de 1931, da cidade mineira de Pitangui. Na carta, agradece os comentários feitos a seu livro Poemas, publicado no ano anterior (lamentando, por outro lado, os comentários ao mesmo volume feitos por Agripino Grieco). O último documento que encerra tal diálogo é o texto comemorativo dos 80 anos de Tristão de Athayde, escrito em 1973 por Murilo Mendes, intitulado Saudação a D.Quixote. 4

Na primeira escreveu:

Prezado Alceu,

Li o seu artigo que me conforton sobremodo - não tanto pelos elogios que contém - mas pela justez̧a de certas observações. Você disse o essencial sobre o meu livro. É claro que, se dispusesse de mais espaço, poderia entrar em maiores detalhes - mas dentro daquelas reduridas duas colunas você tinha mesmo que espremer seu pensamento. Vejo que você me toma a sério, o que para mim é muito importante: não ver no sujeito dos "Poemas" um jogral, nem um mistificador mas sim um indivíduo dissociado, mas que se esforça por atingir uma ordem. Já o mesmo não viu, por exemplo, o Agripino Grieco — cujo artigo, aliás, me serviria mesmo muito se en pretendesse forçar a atenção do público — o que não é o caso dum sujeito que publica sem nenhum aviso, e tira só 200 exemplares, sendo 100 fora do comércio. O Grieco censura minha irreverência, como se o livro todo fosse em tal tom. Entretanto, é só uma parte, e um pouco da $2^{a}$. - poemas, aliás, que eu introduæ̣i ali mais para documentação; como é fácil verificar (a data da composição está indicada no frontispicio) os tais poemas-piadas foram escritos em 1925. Aliás, não abandonei tais manejos - exercito sempre assuntos ligeiros, que épara não ficar muito pesadão na horinha do apocalipse. Tenho horror às comadres, 
arranjos, etc — se the mando dizer isto, éporque vou dizer o mesmo, e mais ainda, por estes dias, ao Grieco — que tem, aliás, algumas anotações muito certas no seu artigo. Espero com o meu próximo livro, que está entrando para o prelo, afastar a queixa, justa, da monotonia dos temas e da técnica fatigante - e não desmerecer a confiança de meia dúz̧ia de sujeitos a cuja opinião dou apreço, e entre os quais se conta você, naturalmente. [...]

Na carta escrita em Pitangui, registro histórico dos momentos iniciais dessa longa amizade, Amoroso Lima é para Murilo Mendes o crítico literário que primeiro soube reconhecer seu valor de poeta. Outro documento, desta vez retirado da correspondência de Alceu com Laís Corrêa de Araújo, escrito em 6 de abril de 1970, o crítico recorda, entretanto, que o primeiro encontro com o poeta foi "anônimo".

Recebi certo dia, lá pelos idos de 1920, um rolo de papel escrito no verso de folhas impressas do Banco Boavista, contendo poesias escritas à mão ou à máquina, não me lembro bem. Fiquei encantado com elas e escrevi, não sei mais em que dia, um rodapé no O Jornal sobre esse desconhecido que me parecia revelar uma força poética nova e profunda, com extraordinário senso de humor. Era o tempo, para ele, da famosa poesia piada com que Murilo Mendes ingressou no rol dos nossos big shots do modernismo e entre eles passou a ocupar lugar à parte. $^{5}$

Tratava-se dos mesmos poemas-piadas que despertaram ácidos comentários críticos de Agripino Grieco e, em Murilo, a necessidade de justificar tanto humor. Esses poemas, escritos em 1925, como frisa o poeta mineiro, saíram publicados em 1932, com capa de Di Cavalcanti; na carta escrita em Pitangui, porém, um ano antes da publicação de História do Brasil, Murilo diz ter tomado cuidado para que o tom da piada não se impusesse. Quando prepara para a 
Editora José Olympio a coletânea de toda sua obra publicada até 1959, os polêmicos versos serão excluídos. ${ }^{6}$

$\mathrm{Na}$ verdade, a carta que Amoroso Lima escreve para Laís Corrêa de Araújo, já em 1970, é uma resposta às dúvidas encaminhadas pela pesquisadora da obra de Murilo sobre a conversão do poeta ao catolicismo. O crítico católico apresenta a conversão em termos bem mais discretos do que, os comumente usados quando se trata do assunto. Reafirma a importância do pintor e amigo Ismael Nery, sugere as conferências realizadas no colégio Santo Inácio pelo Padre Leonel França, promovidas pelo Centro Dom Vital, como elemento decisivo. E acrescenta:

Não creio que tivesse sido nenhuma iluminarão do tipo de Frossard on de Claudel, mas um trabalho lento do tipo de Newman, embora do ponto de vista estético, sempre fundamental em Murilo, e não teológico.

Será que as palavras de Tristão de Athayde, ditas há uma distância de 36 anos do acontecimento, poderiam ser interpretadas como um comentário à conhecida cena da conversão de Murilo ao catolicismo, ocorrida durante o velório de Ismael Nery, em 1934?

Pedro Nava, no volumes seis das suas Memórias, dá a sua interpretação. Depois de ter descrito a doença de Nery e a presença constante de Murilo, ao lado do amigo, narra o momento da fulguração. Comparada, inevitavelmente, à conversão de são Paulo, o alter-ego de Nava, a personagem do médico Egon, diz ter desistido de ministrar uma dose de gardenal porque o que, naquele momento, acontecia a Murilo era mais complexo... O que ele está é sendo arrebatado num êxtase e o que estou vendo é o que virem os acompanbantes na estrada de Damasco quando Saulo rolou do cavalo e foi fulminado pela luz suprema. Exista ou não essa luz e esse fogo — neles ou na sua impressão o Murilo acabou de encadear-se. ${ }^{7}$ 
A conversão de Murilo, segundo Nava, é inicialmente confundida com uma crise nervosa, passando, em seguida a exercer a função precisa de, aos olhos dos amigos, marcar uma mudança substancial da personalidade. O convertido é um outro homem. $\mathrm{O}$ ritual da conversão possui como modelo exemplar, sem dúvida, o do apóstolo Paulo, na estrada para Damasco.

Nava, ao concluir seu relato sobre o enterro de Ismael Nery, descreve o "outro" Murilo, seguindo à risca o "modelo".

\footnotetext{
Quando três dias depois ressurgiu para os homens, tinha deixado de ser o antigo iconoclasta, o homem desvairado, o poeta do poema piada e o sectário de Marx e Lenine. Estava transformado no ser ponderoso, cheio de uma seriedade de pedra e no católico apostólico romano que seria até ao fim de sua vida. Descrevera volta de cento e oitenta graus. Sua poesia tornara-se mais pura e trazia a mensagem secreta da face invisivel dos satélites. ${ }^{8}$
}

Portanto, enquanto o líder católico, indagado sobre a conversão do amigo e discípulo, tenta despi-la dos enfeites teatrais, o amigo mineiro médico-ficcionista encoraja a preservação da importância do Mistério na vida de Murilo Mendes.

A leitura de tais páginas talvez sugira a pertinência de um estudo que analisasse o que é da convenção quando tais episódios são narrados. No caso de Murilo Mendes, em particular, há um material suplementar disponível, o retrato por ele traçado do amigo Ismael Nery, "quase uma hagiografia".?

Reforçando a desconfiança de que há muito de "convencional" nas narrações do episódio, ao folhear a correspondência entre Murilo e Amoroso Lima persiste a impressão que mesmo antes da conversão é possível falar de Murilo como "ponderoso, cheio de uma seriedade de pedra" e também do "católico apostólico romano que seria até ao fim de sua vida”. 
A mesma luz ambígua, que nubla a conversão, desfoca a militância política de Murilo.

Pedro Nava, nas páginas que antecedem seu relato da conversão, descreve Murilo Mendes do ponto de vista político.

"Um esquerdista dos mais exaltados, professando o marxismoleninismo convictamente, sem contudo ser militante. Ao que consta ele nunca foi filiado ao partido comunista Mas pregava seu credo social pela palavra aos amigos, aos conbecidos, aos desconbecidos com quem acontecia falar, e estes eram muitos, nas ocasiões em que lhe tinham desejos de protestar contra os absurdos de nossa terra [..]. Murilo sentia isso como ninguém e trovejava contra - aos gritos, aos berros — onde estivesse — andando nos logradouros, dentro de seus locais de trabalho, nas mas, nos bondes, nos ônibus, nas barcas, nos cinemas, nos teatros, nas festas, nos funerais, a grupos escassos on a multidões se apertando para entrar nos trens de subúrbio. E protestava também [...] abrindo seu guarda-chuva nas salas apinhadas dos cinemas, dos teatros, das reuniões civicas com oratória fremente, das academias em sessão solene.

Imagem com tons surrealistas e quixotesca, o Murilo "político" de Nava contrasta bastante com o auto-retrato de militante que o próprio Murilo esboçou em carta para Alceu, escrita ainda em Pitangui, em 23 de março de 1931, no mesmo período, portanto, do qual se ocupa Nava, isto é, o da pré-conversão.

Prezado Alceu

No mês passado escrevi-lhe uma carta. Uma revista do Rio publicon uma notícia sobre men livro: "livro notável, apesar de elogiado por T. de Athayde". Isto é um indice do tempo! O Brasil suicida-se. Basta abrir um jornal para ficar arrepiado. Neste sossego mineira tenho refletido sobre a atitude dos intelectuais em face do caso brasileiro. Pensei mesmo em me enfiar em algum movimento sério. Fiquei esperando os programas e manifestos. O de São Paulo é ridículo, 
atrasado e literário. O de Minas é mais equilibrado, mas platônico. Ficarão os intelectuais do Brasil reduzidos à situação de "clérigos" que traíram? Ainda pra se julgar isso com segurança, seria preciso definir o conceito de ação... a mim, acho que a ação pode implicar romantismo. O espírito romântico é o de desordem e revolução. O espirito clássico é o de ordem. Este século é profundamente romântico. Há certas atitudes contemplativas muito fecundas. Se eu conseguir escrever um grande poema, terei trabalhado mais para o Brasil do que se fosse pra praça pública pregar liberalismo, etc, à multidão. Para qualquer classe que me transfira, serei infeliz: [...]

Talvez ajudado pela distância no tempo e pelo que já foi dito sobre a tendência em Murilo Mendes a mitologizar os dados autobiográficos, Amoroso Lima faça transparecer a percepção de que havia, no catolicismo de Murilo Mendes, um esteticismo impregnante (Nava, por seu lado, impõe seu tom ficcional ao episódio). Do confronto das lembranças, escritas em registros diversos, de Nava e Alceu, delineia-se, portanto, uma aproximação muito complexa entre estética, religião e política.

Essa proximidade nos sugere, por exemplo, que o "essencialismo", uma espécie de esboço para uma nova formulação do cristianismo, de autoria de Ismael Nery, não citada por Amoroso Lima no seu depoimento e nem lembrada pelo próprio Murilo na correspondência com Tristão através dos anos, ocupava, no esteticismo de Murilo, lugar muito semelhante ao do Surrealismo, sendo difícil avaliar a predominância de um ou de outro, mesmo que a observação se dê através da sua poesia. Até a supressão do tempo histórico, tão definitiva na concepção de mundo e de poesia do poeta mineiro, pode ser tanto cristã "essencialista" (concepção "sacra") como surreal (concepção laica). Voltaremos a isso. 
III.

Entre os livros de Murilo Mendes depositados na biblioteca do CEMM, foi localizado um volume escrito pelo maior representante italiano da chamada crítica hermética. O livro é Scandalo della speranza, coletânea de ensaios e artigos do crítico literário católico Carlo Bo. Murilo fez sua típica anotação (o número da página onde se localiza o assunto, frase ou palavra de seu interesse), a lápis, na última página: "Cristo é a medida do tempo".

A frase anotada é facilmente identificada como uma variação dos muitos versos aforismáticos de Murilo Mendes:

O Cristo é o metteur-em-scène do mundo. (O Discípulo de Emaús, p.825)

Cristo é o nosso mestre de armas. (ib., p.875)

Cristo é uma Pessoa coletiva (ib., p.884)

Jesus Cristo é a civilização (ib., p.885)

O Cristo é mais nós, do que nós mesmos. (ib., p.886)

Pareceria, portanto, que a leitura do livro de Bo fornecia a Murilo um novo verso que é reiterativo do seu catolicismo "essencialista". A fórmula sintética, lapidar, que adotou para sua anotação, ao final da leitura, é reconhecível como da sua própria poética.

O que desperta surpresa é constatar que a frase anotada é o resumo final, feita por Murilo Mendes, da leitura de uma polêmica extremamente significativa, ocorrida entre dois críticos de tendências literárias e políticas bem diferentes, que se deu pouco antes da chegada do poeta a Roma.

O outro volume lido é o Diario in pubblico, de Elio Vittorini. Impressos em 1957, ambos são coletâneas de artigos dispersos em jornais e revistas no decorrer de longo período de tempo (Bo reúne o que escreveu de 46 a 56; Vittorini de 29 a 57). Manuseados e bem conservados, os livros contêm algumas anotações do poeta. Podem 
ser lidos, hoje, como uma súmula das idéias e das discussões que circulavam entre artistas e intelectuais, nos anos que antecedem a chegada de Murilo Mendes a Roma, idéias e discussões que estariam no centro das preocupações de intelectuais e artistas até aproximadamente os meados dos anos 70. São, por outro lado, também importantes por terem registrado uma polêmica específica sobre as relações de Cristo com a cultura e com a história.

O primeiro deles, por ordem de idade, é Elio Vittorini, siciliano de Siracusa, nascido em 1908 e morto, muito moço, em 1966; o segundo, Carlo Bo, nascido em Gênova, em 1911 e morto recentemente, em julho de 2000. Apesar dos poucos três anos de diferença de idade, não são representantes da mesma geração. Ao se referir à "velha crítica", da qual fazia parte Carlo Bo, e às suas atividades no período posterior à segunda guerra, Giuseppe Leonelli comenta que embora esses críticos continuassem escrevendo e interferindo na vida cultural, na verdade, estavam liquidados. Não constituíam mais o centro da vida literária, como no período que antecedeu a guerra, quando o hermetismo era ao centro das discussões e das produções. ${ }^{10}$

Bo, continua Leonelli, depois dos estudos juvenis sobre literatura francesa, ocupara a cena, em 1938, com o ensaio Literatura como vida que rapidamente se tornou a bíblia da poesia hermética. Este livro provocou, entre os jovens do seu tempo, mais do que uma adesão à poética, entusiasmada profissão de fé numa literatura que se apresentava como a "única razão de ser". Contrários à retórica dannunziana tanto quanto à fascista, andavam à procura da "palavra pura", livre de toda intenção comunicativa, atemporal, numa clara referência à experiência empreendida pela poesia francesa a partir do simbolismo. Enquanto crítico, Bo lia e interpretava seus autores prediletos daquela primeira hora, como Giuseppe Ungaretti, Salvatore Quasimodo, Alfonso Gatto, Mario Luzi, à luz de suas "poéticas da palavra", desinteressava-se por posições de classe, 
inscrição no momento histórico ou trajetória psicológica. A "literatura como vida" foi a fórmula criada pelo crítico para exaltar o valor absoluto dessa poesia e, deste modo, aproximá-la das esferas espirituais. Carlo Bo, na verdade, tornou-se o maior representante da crítica literária católica, na Itália.

Através dessa profissão de fé na literatura, os italianos tomam conhecimento da modernidade européia e da poesia moderna que circulava pelo resto da Europa, principalmente aquela escrita por Mallarmé, Machado, Jiménez, Garcia Lorca e também pelos herméticos italianos, com seus textos densos e opacos. A partir de 1945, com a derrota das forças fascistas e término das administrações aliadas, sopra um novo ar. São criadas revistas, pululam programas empenhados na renovação da cultura e da sociedade. Entre tantas, Il Politecnico, dirigida por Vittorini que trazia as palavras de ordem numa proposta de cultura "de defesa e não mais de consolação do homem". Toda a "pureza", todo o distanciamento tomado em relação à História é não só coisa do passado como motivo para muita autocrítica ${ }^{11}$. É surpreendente, contudo, aos olhos de hoje, ler que em 1946, através da revista de cultura que criara, Vittorini enfrenta uma longa discussão com o Partido Comunista Italiano, mais exatamente com Palmiro Togliatti, Secretário do PCI de 1927 até 1964. As divergências entre ambos - o sentido diverso da aproximação entre Cultura e Política ${ }^{12}$ — são menos importantes do que o fato, tão revelador do clima da época e da especificidade da história italiana, de ser possível uma interlocução direta entre as duas personalidades.

Voltando à polêmica.

No primeiro número de Il Politecnico, de 29 de setembro de 1945, Vittorini dedica um certo espaço à figura simbólica de Cristo. O valor possível de Cristo e do Cristianismo, para alguém que não crê, é o da passagem da salvação individual do homem para a salva- 
ção coletiva. Com esse espírito escreve Cristo como cultura, artigo ao qual Bo reage veementemente.

A resposta do crítico católico faz parte da sua coletânea de artigos e ensaios citada: Cristo não é cultura, assevera Bo. Entre seus argumentos está a consideração que Vittorini é uma "natureza religiosa", mas só que não vai até as últimas conseqüências de suas afirmações e também não sabe o quanto está próximo de atingir a mensagem à qual aspira. Continuando a comentar o artigo de Vittorini, diz não lhe interessar discutir o conceito que o escritor tem de cultura, mas mesmo estando próximo a seu ponto de vista não pode concordar totalmente:

Não posso aceitar uma identidade absoluta entre o dominio do espírito e aquele da alma como me recuso a incluir o nome de Cristo entre o de Platão e o de Croce".13

Bo comenta, na mesma resposta a Vittorini:

Neste sentido ficamos muito perplexos com sua esperança de um mundo "reduzido", "renovado", irreconbecivel: são utopias, o católico sabe que o mundo é insuperável, ou melhor, é necessário, assim como o pecador conta mais do que o santo. [...] Os remédios sobre os quais Vittorini deposita sua esperança não nos podem dar nenbuma ajuda; estamos prontos para combater a seu lado contra a injustiça, mas algo dentro de nós nos adverte que essa injustiça começa em nós [...] Vitttorini cita nomes e eu também grito contra essas figuras meu desejo de justiça e de verdade, mas imediatamente tenho que me por no lugar desses homens e observar a minha conduta"14

Para encerrar, arremata:

Enfim, entre o católico e o comunista o ponto de partida pode ser igual, mas onde o comunista pára, o católico sente que tem muito caminho pela frente, talvez o caminho inteiro. "15 
Em novembro de 1945, sempre em Il Politecnico, o escritor siciliano responde a $\mathrm{Bo}$, na forma de uma carta.

\footnotetext{
Vocês católicos deveriam se preocupar também com aqueles que "não crêem" e ver em Cristo não somente aquilo que pode ser para vocês, mas também aquilo que pode ser para os que "não crêem"; cuidar do que Cristo é para você, mas também do sentido de Cristo para aqueles que "não crêem". Cristo pode ser muito importante como cultura somente, não menos importante do que é como fé ou vida para os fiéis [...] Você me responde que Cristo não é cultura. Isso quer dizerer então que não se possa fazế-lo valer como cultura? Que não se possa fazế-lo valer para quem não é seu seguidor? ${ }^{16}$
}

A já citada frase - Cristo é a medida do tempo — um verdadeiro aforismo que poderia constar do livro O Discipulo de Emańs, surpreende porque, por um lado, apresenta, de forma sumária, toda a polêmica e os comentários sobre ela, explicitando o movimento de abstratização - do particular para o geral — tão característico em Murilo Mendes, poeta preciso, elegante e universal; por outro, talvez nos fale, mais a baixa voz, dos limites de um estrangeiro que vive numa cultura que não a sua. Assim, ler Vittorini não significou um mergulho nas idéias que circulavam no período; ler o católico Bo não trouxe Murilo para o cerne das questões católicas italianas. ${ }^{17}$

A polêmica entre os dois críticos traduz as perplexidades que, no pós-guerra, atingem os intelectuais italianos, de modo geral. Idealismo crônico, catolicismo identificado com a Democracia Cristã, modernização do país lenta e pouco democrática, ausência de uma revolução industrial e de uma revolução burguesa são tópicos recorrentes das acirradas discussões que ocupam os jornais e as revistas da época, nas três décadas que seguem a $2^{a}$. Guerra. Nesse sentido a surpresa pela anotação feita por Murilo Mendes, após a leitura dos argumentos de Bo e Vittorini: é como se o poeta ainda 
estivesse, de alguma forma, às voltas com os modos de ação política e as questões do ambiente cultural brasileiro.

IV.

Sabemos, entretanto, graças ao importante trabalho de Murilo Marcondes de Moura sobre as relações entre a poesia e a história, na obra de Murilo Mendes, que o poeta foi plenamente atingido pelo clima de guerra. Para o crítico brasileiro, 1945 é um marco na poética muriliana; O Discípulo de Emaús, livro escrito em 1943 e publicado em 1944, o primeiro resultado da nova poética, alterada a partir da experiência da $2^{\text {a }}$. Guerra. ${ }^{18}$

Portanto, quando Murilo Mendes se transfere para Roma, em 1957, carrega consigo as marcas da guerra que já se faziam notar na sua poética e no livro O Discípulo de Emaús. Ao se transferir, como todo estrangeiro, se vê as voltas com um novo contexto histórico e cultural, com particularidades, fissuras e sutilezas dificilmente perceptíveis num primeiro momento. O retrato mais completo que temos de Murilo nesse período foi feito pela grande ami$\mathrm{ga}$, interlocutora privilegiada desde as primeiras horas de Murilo em Roma, Luciana Stegagno Picchio que dedica, na Introducão Geral da edição de Prosa Completa e Poesia, organizada por ela, um longo trecho à inserção do poeta mineiro ao novo ambiente.

Em Roma, em 1957, depois da missão cultural que o tinha levado à Bélgica, à Holanda, mas sobretudo à Paris da sua identificação cultural, o professor Murilo Mendes chegava com fama de católico evangélico, pois o seu era um catolicismo de regresso, recuperado no convívio com o pintor modernista e o teorizador do "essencialismo" Ismael Nery; e um catolicismo que Murilo logo depois fixaria esteticamente no volume escrito de parceria com Jorge de Lima, Tempo e eternidade. Chegava também munido dum diploma de antifascismo, pessoa não aceita na Espanha franquista, diploma confirmado, por assim dizer, afetivamente, pela 
presença a seu lado da esposa, Maria da Saudade Cortesão, filha do grande historiador e líder do antifascismo português, exilado no Brasil durante as décadas de 1940 e 1950, Jaime Cortesão. Mas sobretudo chegava com a sua fama de católico culto, à maneira francesa, isto é, amigo de Béguin e dos intelectuais que andavam à roda da revista Esprit, de homem que no Brasil freqüentara personagens oximoras como Vieira da Silva e George Bernanos, e que mais recentemente estreitara relações com toda uma inteligência modernista e democrática de escritores e poetas de vanguarda ou não, mas sempre de primeira linha (Albert Camus, Jorge Guillén, René Char, Gheldérode, Henri Michaux) e da qual constavam também, como depois na Itália, os artistas plásticos (René Magritte, Arp, Marx Ernest e, sobretudo, Alberto Magnelli), que nele tinham reconbecido o interlocutor atento e congenial. ${ }^{19}$

Murilo chegava a Roma, portanto, com "fama de católico evangélico", com "fama de católico culto", como já tendo fixado esteticamente seu "catolicismo de regresso" em livro e, informação não menos importante, é recebido como antifascista. Esse "católico culto" soube também procurar e alimentar a amizade, os encontros e trocas com intelectuais não só italianos, principalmente com aqueles que poderiam de forma mais direta responder às suas questões estéticas e criativas.

Esse é o breve perfil escrito pela amiga, que se viu incumbida de devolver, em 1993, dezoito anos após sua morte, uma imagem de poeta brasileiro aclimatado ao mundo da cultura européia e italiana. A nós, leitores brasileiros, é deixado imaginar como se deu esse percurso, o quanto teria Murilo embebido suas roupas com as águas do Tibre, que da sua fama histórica já guardava muito pouco, tendo se transformado nesses anos todos em mais um rio poluído de uma cidade moderna.

O citado "diploma de antifascismo" nos leva a pensar numa perfeita sintonia de Murilo com os inúmeros intelectuais e artistas que irá conhecer e que serão registrados como freqüentadores dos 
míticos apartamentos do casal Mendes, primeiramente no viale Castro Pretorio e depois na via del Consolato ${ }^{20}$, em Roma. Nomes como os de Alberto Moravia e Elsa Morante, por exemplo, indicam como inexorável a discussão política dos rumos da sociedade e da participação da cultura nessa transformação. Moravia foi, principalmente nas décadas de 1950, 1960 e 1970, não só o escritor talentoso de uma obra inaugural como Gli indiferenti, mas um ponto de referência na vida cultural romana; Elsa Morante, escritora e, na época, casada com Moravia, teve importante função como observadora atenta e meticulosa dos caminhos tomados pelos italianos na reconstrução do país e da sociedade após as guerras ${ }^{21}$. Outros nomes como o de Rafael Alberti, Ignazio Silone reconduzem a um clima de época, a uma definição das idéias circulantes como primordialmente de esquerda, de inspiração marxista e comunista.

No retrato muito bem desenhado de Luciana Stegagno Picchio, contudo, é sugerido o deslocamento de Murilo em relação ao mundo cultural e político italiano, mas pelo seu avesso. Pela admiração e profundo respeito ao brasileiro, e compensando-o com o círculo de antigos refinados, Luciana inverte a situação que é a do estrangeiro - culto ou não — que deve se inteirar de uma outra história e de uma outra geografia, deixando entre parênteses a história e geografia que lhe são, acima de tudo, afetivamente próprias.

Há registros, diretos ou indiretos, da angústia sofrida por Murilo Mendes como estrangeiro em Roma. Um deles aparece na intensa expectativa sobre o ensaio que estava sendo organizado pela pesquisadora Laís Corrêa de Araújo, para que contivesse provas do reconhecimento de seu valor poético pela crítica européia. Num comentário a uma carta recebida em 28 de julho de 1972, com o ensaio já pronto, na qual Murilo se mostra profundamente feliz com o resultado alcançado, a estudiosa diz: 
O entusiasmo de M.M. tem a mesma dimensão do seu sentimento de rejeição pelo público brasileiro. Perfeccionista, gostaria de ter administrado a composição gráfica do livro. Preocupa-se com a sua divulgação, pelo que significa de reconhecimento da sua obra. O poeta vivenciou uma experiência dilaceradora, a de não pertencer a nenhum "universo literário". Afastado geograficamente do Brasil, foi efetivamente desligado dos quadros intelectuais do pais - e, na Itália, apesar das amizades que fez não era um "europeu" integrado naquela cultura. ${ }^{22}$

Outro registro desse deslocamento de estrangeiro de Murilo, faz-se notar numa carta enviada a Amoroso Lima, em $1^{\circ}$. de junho de 1963.

Continuamos nossa vidinha romana, até que possamos regressar ao Brasil. As noticias que nos chegam dai são assustadoras, mas ainda assim benzerei o dia que tivermos de regressar. Por mais internacional e universalista que me sinta, constato que dia a dia sou mais brasileiro e mineiro. O Brasil tem um encanto irresistivel. E com todos os seus defeitos, on ne s'y ennuie jamais.

$V$.

As décadas nas quais Murilo vive na Itália, as dos anos 50, 60 e 70, são particularmente intensas e têm como marco inicial as repercussões da segunda guerra. Ao contrário da primeira, a segunda guerra mundial produziu como efeito evidente o profundo cruzamento e a profunda renovação das idéias, responsável por uma das mais efervescentes épocas culturais da contemporaneidade italiana. Após o término da primeira, os intelectuais e artistas que haviam acreditado na guerra como libertadora, se viram como os vencidos; no segundo período, a nova geração pode acreditar que saía vencedora. ${ }^{23}$ No início do século o que se apresenta como estado de ânimo é a melancolia, a frustração, com o apoio a políticas conservadoras; os intelectuais da nova cultura, ao contrário, alimen- 
taram fartamente a esperança de serem os cérebros de uma política de renovação. $\mathrm{O}$ que os distingue sobremaneira é a experiência social e política da resistência ${ }^{14}$.

A discussão sobre a importância histórica maior ou menor da resistência só vale ser citada aqui porque é, sem dúvida, a experiência, tanto social, como política e cultural, que parece ter deixado as marcas mais profundas em Vittorini ${ }^{25}$ e que parece indicar um dos elementos diferenciadores das duas gerações que distinguem, segundo Leonelli, o crítico Bo do crítico Vittorini. O antifascismo hesitante que caracterizou tão bem a reação dos intelectuais nas primeiras décadas do século XX, incluídos entre estes Carlo Bo, é levado a superar-se no antifascismo militante, encorajado a assim se definir pela formação das Brigadas Internacionais Antifascistas e pelo início da Guerra da Espanha, em 1936.

Não há, entretanto, reflexos evidentes deste assunto candente - a resistência - nas cartas ou na própria obra de Murilo Mendes. Além disso, nomes como os de Franco Fortini, Pier Paolo Pasolini, Italo Calvino, entre tantos outros, destacam-se como ausências numa obra como a do poeta mineiro que usa de seus retratosrelâmpago, para comentar e homenagear nomes da contemporaneidade. Não que obrigatoriamente devesse citá-los ou homenageálos; são, entretanto, pelo lugar e importância que ocupam no panorama das idéias, ausências significativas.

Invertendo-se a direção do olhar, procurando no autor que se "exilou" por tantos anos na Itália, os traços de sua adaptação à cultura e à vida romana, é possível enxergar na finalização do retrato escrito por Stegagno Picchio outras faces do poeta. A constante e militante discussão entre católicos e marxistas, aqui representada nos primórdios da modernização da sociedade italiana, pela polêmica entre Bo e Vittorini, as reflexões sobre as experiências italianas do pós-guerra e da resistência, não são sentidas como ausências talvez porque Stegagno Picchio, profunda conhecedora da cultura 
brasileira e de muitos intelectuais brasileiros, situe Murilo na Itália, em Roma, mas como participante de uma comunidade "universal", a dos criadores.

Muito do surrealismo de Murilo Mendes, cuja obra sobressai na literatura brasileira ao lado de Jorge de Lima como uma das poucas áreas tocadas pelo verbo de Breton, passa por estas amizades, embora existisse uma predisposição ao "surreal", antes ou além das modas e dos credos de escola. Como escreven José Guilherme Merquior "do surrealismo é imperativo dizer-se que, para Murilo, ele foi principalmente, por paradoxal que pareça, uma disciplina, um rigor, uma ascese poética" [...]

Quanto sofreria um homem assim na Itália dos anos 50, 60, 70. Na Itália da politique d'abord, em que os escritores eram todos marxistas ou "companheiros de luta", em que os católicos eram reacionários e só se ocupavam de politica, e onde a cada momento era preciso situar-se, tomar partido, assinar manifestos. Coitado do Murilo, católico evangélico, cantor de um Cristo pobre e de uma Igreja essencialista e das origens, coitado do Murilo forçado a pôr em causa as suas conviç̧ões e os seus ideais: que na Cidade Eterna do martírio de São Pedro e São Paulo, via o papa levado em palanquim como um monarca oriental, rodeado pelos flabeliferos, enquanto o povo ficava longe, aclamador e excluido. Não é verdade que Murilo em Roma tenha perdido a fé: mas é verdade, sim, que ele perdeu a fé naquele tipo de sociedade, de Igreja e de religião. E só pareceu reencontrá-la e reencontrar-se quando ao sólio de Pedro ascendeu o bondoso, revolucionário, modernissimo papa João XXIII. ${ }^{26}$

Sem dúvida alguma, para Murilo Mendes, João XXIII foi o vento da renovação que soprou sobre a igreja italiana e universal ${ }^{27}$, momento do entrecruzamento, na Europa, de idéias marxistas e católicas, mas o viés do Mistério, que viola todos os limites da razão é demasiadamente forte e presente em Murilo e aproxima inexoravelmente proposições que vem do surrealismo a do seu catolicismo - ou vice-versa (O surrealismo, tentando ultrapassar os limites da 
razão humana, aproxima-se às vezes consideravelmente da mistica, O Discípulo de Emaús, p.822). Nesta hipótese, ambos teriam a função de manter ativo o Mistério que o poeta dizia ser absolutamente necessário para sua poesia e para sua vida. E dele Murilo dependia há muito tempo, desde as terras de Minas, como escreve a Amoroso Lima, em 8 de março de 1936:

Minha vida espiritual de vez, em quando sofre colapsos. A excessiva clareza dos dogmas do catolicismo me impede de mergulhar no mistério; e eu preciso continuamente do mistério.

Da mesma forma, a Murilo pareceria extremamente limitante o projeto social, político e cultural do marxismo porque nele não haveria lugar para a Paixão, momento crucial da instalação do Mistério. (A Revolução é economicamente necessária - mas filosoficamente e espiritualmente errada. O Discípulo de Emaús, p.843/ A doutrina comunista tira sua força do fato de ainda ser uma paródia do grande dogma da comunhão dos santos. Ib., p.845/ Jamais a política e a economia terão a força da mistica. Ib., p. 862)

Concluindo, o "Cristo é a medida do tempo", verso "espontâneo" anotado no final de um livro lido, revela, por um lado, o Murilo "estrangeiro", sempre a uma certa distância dos eventos e acontecimentos da Itália; por outro, pelas correspondências estudadas, é também possível apontar para sua ligação continuada com o ambiente brasileiro, em particular, o do catolicismo.

Em síntese, é como poeta que Murilo vive em Roma: a busca do Mistério, quase a qualquer custo, que envolvia, como um manto fino, Murilo Mendes, é a água fresca para sua criação: a supressão do tempo, implícita nas formulações do essencialismo de Ismael Nery e encontráveis nas formulações do surrealismo, é o pressuposto para que haja uma solução poético-religiosa para Murilo dilacerado pela guerra. 
Giorgio Agamben comentando "a experiência cristã do tempo" afirma que enquanto a representação clássica do tempo é um círculo, a imagem que guia a conceitualização cristã é a da linha reta. Ao contrário do helenismo, o mundo é, para o cristão, criado no tempo e deve acabar no tempo. De um lado, o relato da Gênesis, do outro, a perspectiva escatológica do Apocalipse. E a criação, o Juizo Final, o periodo intermediário que se desenvolve entre os dois eventos, são únicos. Este universo criado e único, que comecou, dura e acabará no tempo, é um mundo finito e limitado pelos dois lados da sua história. Não é nem eterno, nem infinito na sua duração, e os eventos que nele se desenvolvem não se repetirão jamais (Puech) ${ }^{28}$. Talvez assim se possa entender um pouco mais o essencialismo de Ismael Nery e Murilo Mendes: a alteração da experiência cristã do tempo proposta garante ao poeta o eterno desconhecido e a mística do catolicismo.

Para finalizar, há, sem dúvida, um outro tema a ser investigado: habituados a que estamos a decifrar o estrangeiro que vem a nossa terra e a ela se incorpora, com maior ou menor entusiasmo, perdemos de vista o intelectual ou artista brasileiro que se "exila" na Europa e lá faz sua experiência de "estrangeiro". São inúmeros os nomes registrados na História Literária. Há semelhanças e diferenças, com certeza reveladoras, entre, por exemplo, as estadias de Murilo Mendes, de João Cabral de Melo Neto e de Vinícius de Moraes na Europa. É um grande assunto ainda a ser explorado.

\section{Notas}

1 Livros e obras de arte pertencentes a Murilo Mendes foram entregues por sua mulher, Maria da Saudade Cortesão Mendes, à Universidade Federal de Juiz de Fora e se encontram atualmente no Centro de Estudos Murilo Mendes Juiz de Fora - MG). Consta que Murilo teria determinado que as obras de autores brasileiros de sua biblioteca particular devessem permanecer na Universidade de Roma e as de autores estrangeiros, no Brasil. 
2 Um dos resultados é o catálogo da exposição Murilo Mendes 1901-2001, inaugurada em 13 de maio de 2001. Outro, não menos importante, foi o concurso de monografias sobre o autor, tendo como vencedoras Irene Franco e Joana Matos Frias, ambas colaboradoras deste número da Remate de Males, dedicado a Murilo Mendes. No mesmo centro, ainda no ano passado, foi realizado um seminário sobre o autor.

3 Maria de Lourdes Eleutério escreveu, neste número da revista, sobre Murilo Mendes, colecionador.

4 Murilo Mendes. Poesia Completa e Prosa, org. Luciana Stegagno Picchio, Rio de janeiro, Editora Nova Aguilar, 1995, p.1478.

5 Laís Corrêa de Araújo, Murilo Mendes. Ensaio crítico. Antologia. Correspondência, São Paulo, Perspectiva, 2000, p.371.

6 Como curiosidade, entretanto, há outra exclusão pouco notada. Passados tantos anos, e tanto já tendo sido dito sobre as relações de Murilo Mendes com os modernistas, constatamos que enquanto reiteradamente críticos e estudiosos - o próprio autor, antes de qualquer outro - justificam a exclusão de História do Brasil da coletânea de 1959, há uma outra ausência: pouco se alude ao livro escrito em 1936, também deixado de lado - O sinal de Deus - e quase não se indaga sobre as razões dessa outra exclusão. 7 Pedro Nava em Círio Perfeito, Rio de janeiro, Nova Fronteira, 1983, pp. 276-283 e pp. 313-319. A lembrança de tal descrição está em Murilo Marcondes de Moura, Murilo Mendes. A poesia como totalidade, São Paulo, Edusp/Giordano, 1995, p.43, nº 58.

8 Pedro Nava, op.cit. p. 319.

9 São palavras de Murilo Marcondes, op.cit. O material sugerido é o livro Recordações de Ismael Nery, pref. Davi Arrigucci Jr., São Paulo, Edusp/Giordano, 1996.

10 Giuseppe Leonelli. La critica letteraria italiana (1945-1994). La letteratura tra politica e scienza dagli anni dell'impegno alla fine delle ideologie. Milão, Garzanti, 1994.

11 No número de Il Politecnico, de 16 de janeiro de 1946, aliás, Vittorini traduziu e publicou, em primeira página, o artigo de Sartre que inaugurou Le temps modernes. O filósofo francês dizia:

\footnotetext{
Não existe a menor chance de evadir-se da sua própria época, queremos portanto abraçá-la fortemente. Sentimos pela indiferença de Balzac às jornadas de 48, a incompreensão assustada de Flaubert diante da Comuna ... Nós não queremos fal-
} 
tar a nada do nosso tempo ... mesmo se fôssemos mudos e quietos como pedras, nossa própria passividade seria uma ação... (G. Leonelli. op. cit., p.16-17.)

A perplexidade de Sartre e de Vittorini é reafirmada no Brasil, numa declaração feita por Anibal Machado sobre a necessidade de engajamento dos artistas daquele período: "poetas vários, reagindo cada qual à sua maneira, debaixo do mesmo céu de trevas e pressentimentos [...] sairam todos de suas nuvens para o encontro com os acontecimentos, se é que os acontecimentos não foram buscá-los ao reino do sonho para atirá-los aos campos de luta e morte". A citação faz parte de "A Poesia na resistência a Francesa", Literatura, Ano I, no 2, Rio de janeiro, out.1946, pp. 14-25 in Murilo Marcondes de Moura, op.cit. p.165 e nº 25.

12 Giuseppe Leonelli, op.cit., pp.26-27, $\mathrm{n}^{\circ} 22$.

13 Carlo Bo, op. cit., p.86

14 Carlo Bo, op. cit. p.87.

15 Carlo Bo, op. cit. p.89.

16 Elio Vittorini, op. cit., p. 192

17 Há na prosa de Vittorini, mesmo quando escreve seus textos de intervenção política, um forte lirismo. Ao escrever sobre Albert Béguin, em dezembro de 1958, Murilo Mendes utiliza, para terminar seu texto, um trecho do autor siciliano: Il mondo è grande ed è bello, ma è molto offeso. Tutti soffrono ognuno per se stesso, ma non soffrono per il mondo. Che è offeso... (Diálogo, no 10, São Paulo, pp.55-68, cit. in Murilo Marcondes de Moura, op.cit., p.174 e $\left.\mathrm{n}^{\circ} 33\right)$.

18 Para as variações e alterações das concepções poéticas de Murilo Mendes consultar, entre outros, Murilo Marcondes de Moura, op.cit. e sua tese de doutorado Três poetas e a Segunda Guerra Mundial (Carlos Drummond, Cecília Meireles e Murilo Mendes), Departamento de Teoria Literária e Literatura Comparada da Faculdade e Filosofia, Ciências e Letras da Universidade de São Paulo, 1998. Ver também a dissertação de Mestrado de Irene Franco, Pânico e flor: Projeto ético e fazer poético em Murilo Mendes, Departamento de Teoria Literária do Instituto de Estudos da Linguagem da Universidade Estadual de Campinas, 2001.

19 Murilo Mendes. op. cit., p.25.

20 Murilo Mendes, op. cit, p.28. 
$21 \mathrm{Em} 1^{\circ}$. de maio de 1945, após o fuzilamento de Mussolini, Elsa Morante escreve um pequeno artigo contundente, procurando traçar o perfil do italiano através da sua tolerância de um líder definido como "homem medíocre, grosseiro, fora da cultura, de eloqüência um tanto quanto vulgar, mas de efeito fácil [...], exemplar perfeito e espelho do povo italiano contemporâneo. Junto a um povo honesto e livre, Mussolini teria sido ao máximo um leader de um partido com poucos seguidores e autor não muito brilhante de artigos verborrágicos no jornal do seu partido. Teria permanecido um personagem provinciano, um pouco ridículo, por conta de seus modos e postura, e ofensivo ao bom gosto das pessoas educadas pelo seu estilo enfático, despudorado e canhestro. [...] $\mathrm{Na}$ Itália foi o Duce. Porque é difícil encontrar um exemplo melhor e mais completo de Italiano". Cit. por Alfonso Berardinelli, Autoritratto Italiano - un dossier letterario 19461998, Roma, Donzelli Editore, 1998, p.30.

22 Laís Corrêa de Araújo, obra cit., p. 180.

23 As idéias aqui discutidas são em parte devedoras de Norberto Bobbio, Profilo ideologico del'900, Milão, Garzanti, 1990.

24 Essa não é, contudo, uma afirmação de Norberto Bobbio que não dá grande crédito para o movimento da Resistência italiana quando, por exemplo, afirma que "o fascismo levara o país à catástrofe, como os antifascistas previram. Mas a Resistência, contrariamente às suas esperanças, não foi palingenética. Não foram necessários muitos meses (da liberação do Norte em abril de 1945 à queda do governo Parri em novembro) para se perceber que o fascismo (...) havia sido um longo parênteses, que após seu fechamento a História começaria mais ou menos do ponto em que o parênteses tinha sido aberto". Norberto Bobbio, op. cit., p. 261.

25 Em Império, Michael Hardt e Antonio Negri (Rio de Janeiro, Record, 2001, p. 469, $\mathrm{n}^{\circ}$. 6) afirmam ser Uomini e no, escrito em 1945 por Vittorini, um dos romances mais importantes da resistência italiana.

26· In Murilo Mendes o cit. 28.

27 [...] Você poderá imaginar o que tem sido minha experiência — três anos em Roma! [...] Viver nas barbas do Papa, às portas da Cúria Romana. Para um católico consciente, que sabe das possibilidades infinitas da Igreja, e vê que muitas delas, e importantes, não são postas em prática, seja pela ignorância de uns, seja pela posição extremamente conservadora de outros - é terrível. [...] 
O Papa — pessoalmente simpaticíssitno, nascido do povo, como você sabe, um antiPio XII, espontaneamente natural (ainda não fez nenhum discurso doutrinário) no começo parecia disposto, com certas atitudes e declarações suas, a reconhecer o interesse e o valor de determinada linha socialista; quando Cardeal Patriarca de Veneza, reconhecia publicamente a ação dos socialistas, dizendo que eles faziam coisas úteis e boas para a coletividade. Houve uma certa fase de "suspense" em que se pensou que algumas coisas se mudariam na linha política da Igreja. Mas em breve os Cardeais do Pentágono barraram ao Papa qualquer veleidade de alteração da linha, como logo se viu no caso da aliança política de uma fração da Democracia Cristã, na Sicília, com socialistas e comunistas $[\ldots]$

Carta a Alceu Amoroso Lima, de 14/03/60, CEMM.

28 Giorgio Agamben. Infanzৃa e storia. Distruzione dell'esperienza e origine della storia, Turim, Einaudi, 2001, p.98-9. 


\section{VIVO EM ROMA:}

VIVO EM ROMA PORQVE POSSO AqUI EXERGER MEU TRABAhHO DE PROFESSOR, ESCRITOR E MEMBRO DE UMA SOCIEDADE SECRETA qUE SE PROPÓE DINAMITAR o monumento de piazza Venezia. PORQUE ROMA, SEGUNDO UM CÉhEBRE SONÊTO de QUEVEDO, NÃO E TÁ MAIS EM ROMA, PORTANTO NATC ME SINTO OBRI = GADO a SEGUIR O Rastro dos CÉsares. PORQVE seu povo é humano e simpático. Porque roma TEM BELAS MULHERES, PRACAS ESTUPENDAS; ÉSTE OCRE DAS SUAS CASAS ME SERVE dE TÓNICO. PORQUE AqUT ENCONTREI AMIGOS Dehiciosos: QUE GERAhMEN TE NAOO CREEM QVE $2+2=4$. PORQVE EM ROMA EXISTE O MUSEU DE UAhhE GIULAA: QUANDO ENTRO ALI ME TRANSFCRMO NUM ETRUSCO. PORQNE KARAMEN TE SE TOPAM RINOCERONTES NOS SEUS PARQVES. Pa QUE É A CIDADE QUE VIVE SOB O SIGNO DO JUIZO UA VERSAL E DA MAIS FORMIDÁVEL HISTÓRIA EM QUSDRAD NHOS, EXATAMENTE O TUÍZO UnIVERSAh de miGUeh a Geho, O « ARRABbiato"POR EXCELÉnCIA. PORQve V veNdo em roma näO sinto necessidade de ir a LUA SOMOS AQUI, TODOS, LUNÁTICOS. PORQNE EM ROMA POSSC VER JOÃO 23, ISTO É, A EXCOMUNHÃ̃O DA BOMBA, O PROGRESSO dO ECUMENISMO E DA PAZ.

VID. VERS -

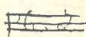


Resposta a UM INQVÉrito da reVISTA 2 ha fiera letteratria" dirigido hos escri tones ESTRANGEIROS RESIDENTES EM ROMA, E Ahi PUBLICADA EM 1963: " PERCHÉ VIVE A ROMA? " 
Acervo Alexandre Eulalio-CEDAE

IEL-UNICAMP 


\section{LA TRAVIATA}

SEM COROS DE APLAUSOS

NEM A SOMBRA DE AKGUM VERDI

ENTRE OS MUROS DO PASSEIO ARQUEOLÓGICO

- ESFINGES de PINHEIROS

VIDA SUBTERRANEA SOLETRADA -

MASTIGANDO HOMENS UAI E VEM

P.ERIPATETICA.

ESPÁDUAS EM POBREZA LE LIVIDEZ

REGUhAM COM SEIOS BEM MUNGIDOS

PERNAS DEMAIS PASSEADAS.

PISOU O OLHAR, O PRÓPRIO CLHAR DECOTAIC.

SABERÁ DESI?

GRANDE SERIA

SE OS ASTROS O QUISESSEM

- SERÁ thLUEZ aNÓNIMAMENTE GXande-

OV A PARTISSE LEVIATA.

NAOO CONSIDERA OS COLEANTES GATOS.

MURMURANDO UM HOMEM, DOIS,

TRITURA CAMÉLIAS PASSIVAS

E UNI, NO CENTRO DA DESAFIADA MORTE, DO SEXO, DÉVIA.

MESCHINA LEI. BEATR LEI. 
Acervo Alexandre Eulalio-CEDAE

IEL-UNICAMP 